\title{
Mitochondrial Dysfunction in Skin and Ocular Surface Disease: An Interdisciplinary Review
}

\author{
Omeed M Memar ${ }^{1 *}$, Benjamin Caughlin² and Ali Djalilian ${ }^{3}$ \\ ${ }^{1}$ Department of Dermatology and Skin Cancer Institute, USA \\ ${ }^{2}$ Department of Surgery and Division of Otolaryngology, USA \\ ${ }^{3}$ Department of Ophthalmology, University of Illinois, USA
}

*Corresponding author: Omeed M Memar, Department of Dermatology and Skin Cancer Institute, Chicago, Illinois, USA.

To Cite This Article: Omeed M Memar*, Benjamin Caughlin, Ali Djalilian. Mitochondrial Dysfunction in Skin and Ocular Surface Disease: An Interdisciplinary Review. Am J Biomed Sci \& Res. 2019 - 1(4). AJBSR.MS.ID.000538. DOI: 10.34297/AJBSR.2019.01.000538

Received: February 20, 2019 | Published: February 27, 2019

\begin{abstract}
Mitochondria are subcellular organelles that are the power-house of the cell. However, we now see that they play an ever-growing role in health, disease and aging of the skin. Not only does the mitochondria produce the most reactive oxygen species (ROS) in the cell, but it affects major inflammatory and dysplastic processes. We have reviewed the literature on mitochondrial dysfunction and ocular surface disease. We have presented syndromes and non-syndromic conditions where mitochondrial dysfunction affects ocular surface health, dry eye, and keratoconjunctivitis.
\end{abstract}

Keywords: Mitochondrial dysfunction; Ocular surface; Keratoconus; Cornea; Tear; Mitophagy; Autophagy; Tear film

\section{Introduction}

Mitochondrial disease is known to affect many aspects of ocular health: the retina, neural elements, carcinogenesis, glaucoma and the ocular surface [1]. The ocular surface comprises of the cornea and conjunctiva and is heavily influenced by the glandular elements present. Here we will focus on the role of mitochondria in ocular surface pathology.

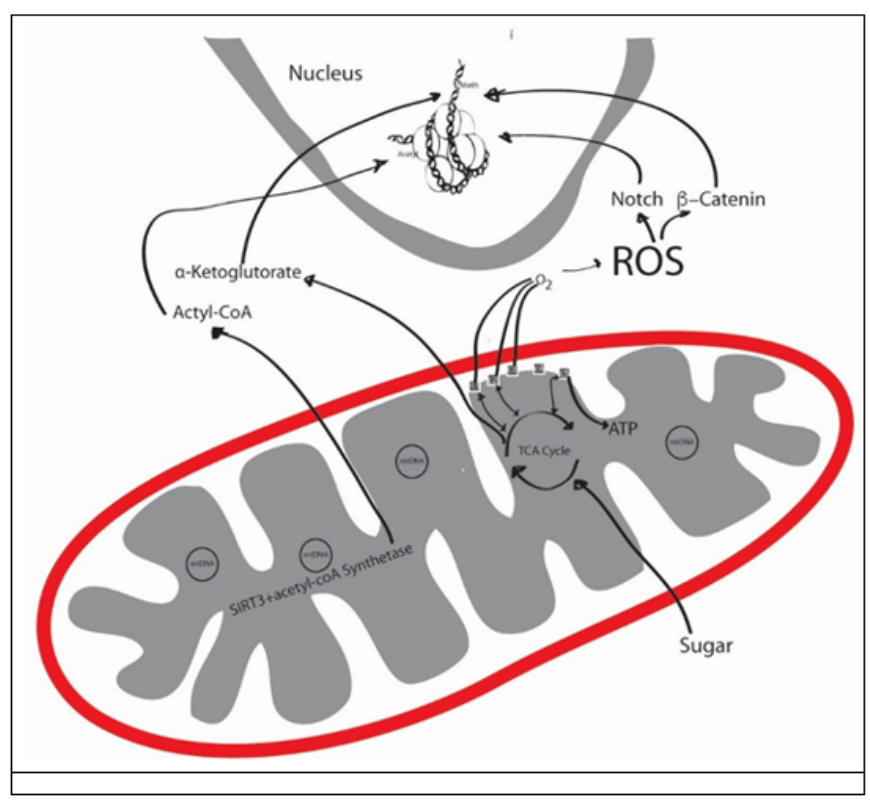

Figure 1: The productions of reactive oxygen species (ROS) by mitochondria, and the interplay of mitochondria with the nuclear DNA. 
Mitochondria are sub-cellular organelles with dsDNA. Mitochondrial DNA (mt DNA) is normally present at thousands of copies per cell and is packaged into several hundred higher-order structures termed nucleoids MtDNA makes only 13 proteins, a noncoding regulatory D-Loop, 2rRNAs and 22 tRNAs, including genes for 13 oxidative phosphorylation (OXPHOS) polypeptides, 22 tRNAs and two ribosomal RNAs, while some of the OXPHOS elements are encoded by nuclear DNA [2]. The function of mitochondria is energy (ATP) formation, heme synthesis, calcium homeostasis, cell signaling, cellular differentiation, cell growth, cell cycling, and cellular death [3]. Here we go deeper into the function and dysfunction of the mitochondria and the ramifications it has on the ocular surface (Figure 1).

\section{Function of mitochondria}

Through OXPHOS, mitochondria use breakdowns of proteins, fatty acids and sugars to generate using c5 (Figure 1). Mitochondria are thought to be of bacterial origin and mitochondrial function is driven by mt DNA, nuclear DNA [4] and epigenetic elements [5]. C1, which is made up of 44 subunits, 37 of which is encoded by nuclear DNA and the rest by mt DNA [6]. However, most c1 mutations have been associated with mt DNA, rather than nuclear DNA, The reactive oxygen species (ROS) form c1 mutations could cause further mt DNA mutations [7]. In these processes, many factors that affect tissue aging and dysfunction are influenced.

ROS are formed in the respiratory chain that normally occurs in the inner mitochondrial membrane, where five multi-molecular electrochemical generators create a gradient that converts adenosine diphosphate (ADP) to adenosine triphosphate (ATP) due to mitochondrial oxidative phosphorylation (OXPHOS) [8]. C1 and C3 are the main producers of ROS [8]. Mitochondria are the main producers of ROS. One difference between nuclear and mt DNA, is that mitochondria lack histones, making mt DNA very susceptible to damage from ultraviolet (UV) rays and ROS [9]. These oxidants might cause a decrease in the electron transport chain (ETC) enzyme activity, inefficiency in ATP production, impaired cellular respiration, nuclear/mt DNA mutations and tissue damage [10].

The other component of the mitochondria is the sirtuin family, specifically sirtuin 3 (SIRT3) [11]. SIRT3 activates acetyl-coA synthetase, which forms acetyl-coA-Acetyl-coA is essential for protien,sugar, and lipid metabolism. SIRT3 resides in the matrix of the mitochondria and mice lacking SIRT3 develop cancer [12]. SIRT3 a protien anti-oxidant, has been shown to protect tissue from ROS [13].

Finally, mitophagy, or the self-destruction of dysfunctional mitochondria plays a large role in health. If the dysfunctional mitochondria are not eliminated, then excessive ROS is produced, causing tissue damage [14].

A balance between the ROS, protective mechanisms from ROS in times of infection, and ultimately mitophagy equal the overall cellular and tissue health (Figure 2).

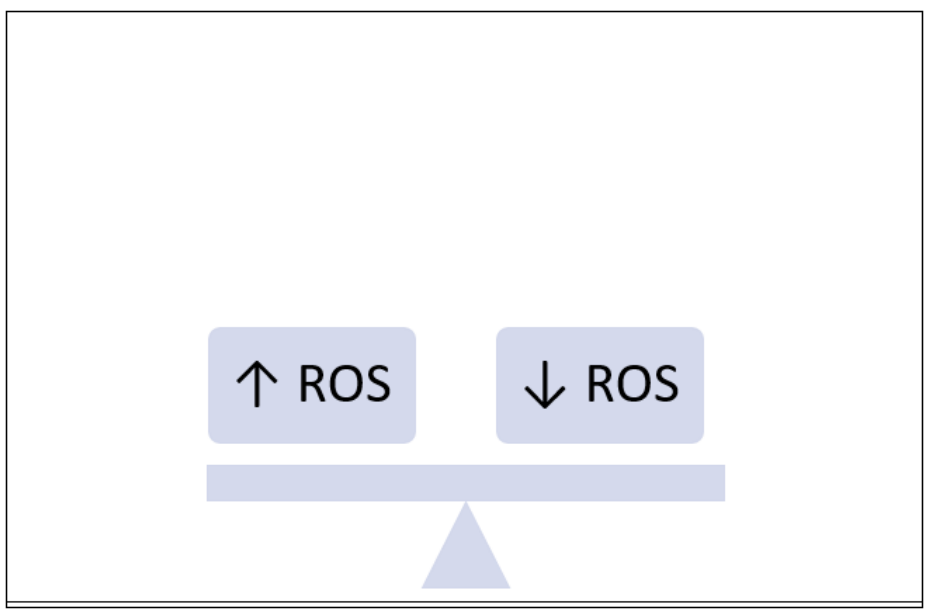

Figure 2: The balance of the right amount of reactive oxygen species (ROS) is the function of healthy mitochondria.

One mechanism of mitochondrial dysfunction is a disruption of mitophagy. Mitophagy is regulated by mechanistic target of rapamycin complex 1 (mTORC1) [15], which has numerous blockers, like rapamycin. Rapamycin can induce mitophagy [16]. In Parkinson's disease, two proteins are known to promote mitophagy in dysfunctional mitochondria: PARKIN and PINK1 [17]. Mutations in PARKIN and PINK1 can lead to an accumulation of dysfunctional mitochondria, an increase in ROS, and Parkinson's symptoms.

\section{Epigenetics in mitochondria}

The epigenetic phenomenon is a nuclear phenomenon, encompassing methylation, micro-RNA (non-coding), sRNAs (noncoding), histone modifications, etc. However, there is mounting evidence of genomic epigenetics cross-talk with mtDNA (Figure 1). Environmental factors, including certain drugs, can influence mtDNA and nuclear DNA in an epigenetic pattern. Due to the above described vulnerability of mtDNA, it is logical that mtDNA is accessible for cross-talk. Reversely, mitochondrial depletion has been associated with altered DNA methylation profiles of certain human nuclear genes. Mitochondrial depletion could down-regulate nuclear DNA repair resulting in DNA damage that is converted into mutations by error-prone repair polymerases.

\section{The role of antibiotics in mitochondrial dysfunction}

Mitochondria are of bacterial origin and many of the antibiotics we use affect mitochondrial function. Mice treated with quinolones, 
aminoglycosides, and $\beta$-lactams produced toxic levels of ROS that showed damage to DNA, proteins and cellular membrane [18]. Furthermore, the tetracycline family of antibiotics has been shown to cause mitochondrial dysfunction [19]. In animal models, tetracyclines cause mitochondrial proteotoxic stress, causing changes in nuclear gene expression and altered mitochondrial function [19]. The fact that depletion can be induced and then reversed highlights the relevance of epigenetics in mitochondrial health [9].

\section{The role of ultraviolet (UV) light in mitochondrial dysfunction}

The number one environmental cause of oculocutaneous aging is UV irradiation from the sun. Mitochondria are especially susceptible to this damage [20]. With aging, the enzymatic activity of mitochondria decreases and there is an increase in mtDNA mutations [21]. mtDNA have a 50 -fold greater mutation rate than nuclear DNA [22]. In humans, it is thought that large-scale deletion of mtDNA, and not point mutations, are involved in UV-induced photoaging [23]. This large-scale mtDNA deletion, or as it has become to be known as the "common deletion" does not correlate with chronological age and seems to be UV specific [24]. When human mtDNA mutations are followed over years, the mutations can increase by 32 folds, even without further UV irradiation. Heat also causes mtDNA damage. Infrared (IR) irradiation causes point mutations in mtDNA in a different deleterious mechanism than UVA or UVB [25]. This is thought to cause a "defective power house" model of premature aging, where there is altered collagen production by fibroblasts, neovascularization and inflammation, all hallmarks of ocular surface aging and dry eye [10].

The role of mitochondrial dysfunction in uncontrolled growth of tissue

Mitochondria have a role in uncontrolled growth of tissue.
For example, tumors are in desperate need of energy and macromolecules, so it is not surprising that mitochondria are important to tumor growth. Mitochondrial dysfunction is intimately involved in skin cancers. Incidence of mtDNA mutations in melanoma and head and neck squamous cell carcinoma has been shown to affect every mitochondrial gene [26]. Keratinocyte differentiation and propagation by Notch and $\beta$-catenin signals are regulated by ROS. Their signaling pathway is also important in skin appendageal development and tumorigenesis [27]. For example, mitochondria are rich in basal cell carcinomas [28], However, ubiquinone, which is important in tagging cells for mitophagy, is consistently downregulated in basal cell carcinomas [29]. Oncocytomas, which are growths associated with Birt-Hogg-Dube syndrome and Cowden Syndrome, are associated with mutations in c1, causing excessive ROS production [30].

The ROS activates a complex structure called the inflammasome. The Inflammasome regulates caspase-1-dependent secretion of IL-1; this process promotes skin cancer formation [31]. The most common BRAF mutation in melanoma induces dysfunctional OXPHOS, and primary and metastatic melanomas have higher expression of OXPHOS than nevi [32]. Mitophagy may have a role in melanoma progression [33]. Therefore, dysfunction in mitochondria is associated with some skin cancers and syndromes associated with internal malignancies.

\section{The role of mitochondria on the ocular surface}

ROS is elevated in dry eye syndromes [34]. Numerous factors can cause an elevation of ROS, but mitochondria are the number one producers of ROS in humans, especially as the mitochondria becomes less functional [35]. For example, dry eye has a reduction of lacritin, a tear glycoprotein needed to induce autophagy in situations of inflammation [36]. The reduction of lacritin in dry eye creates a vicious cycle of inflammatory cells creating greater ocular surface damage (Table 1) [37].

\begin{tabular}{|c|c|c|}
\hline Syndrome & Gene defect & Ocular Surface Findings \\
\hline Sjøgren's Syndrome & Low levels of lacritin & Dry eye \\
\hline \multirow{3}{*}{ Fanconi syndrome } & \multirow{3}{*}{$\begin{array}{l}\text { CTNS (most common formed of inherited type } \\
\text { in children) }\end{array}$} & Astigmatism \\
\hline & & Corneal clouding \\
\hline & & Cystine crystals in children \\
\hline \multirow{2}{*}{ Pearson syndrome } & \multirow{2}{*}{ Large deletions of mtDNA } & Corneal dystrophy \\
\hline & & Corneal endothelial dysfunction \\
\hline \multirow{3}{*}{ Fuchs endothelial dystrophy } & COL8A2 & \multirow{3}{*}{ Glare, haloes at night, blurred vision } \\
\hline & SLC4A11 & \\
\hline & ZEB1 & \\
\hline Animal model & Thrombospondin 1 (THBS1) & Dry eye \\
\hline Animal model & Rab3d, Rab27b, Rab3d or syntaxin & Dry eye \\
\hline Kearns-Sayre syndrome & $\begin{array}{c}\text { mtDNA deletion at bp } 3895 \text { also large mtDNA } \\
\text { deletions }\end{array}$ & $\begin{array}{l}\text { Conjunctivitis complete ptosis, spontaneous } \\
\text { corneal ulceration and keratitis }\end{array}$ \\
\hline Kearns-Sayre syndrome & & Corneal clouding \\
\hline Leigh syndrome & $\begin{array}{l}\text { mutation in mtDNA bp 8993, amongst other } \\
\text { mutations }\end{array}$ & Non-specific corneal changes \\
\hline $\begin{array}{l}\text { Mitochondrial neurogastrointestinal } \\
\text { encephalopathy syndrome }\end{array}$ & TYMP & Non-specific corneal changes \\
\hline
\end{tabular}




\begin{tabular}{|c|c|c|}
\hline Pontocerebellar hypoplasia & Mitochondrial aminoacyl-tRNA synthetases & Corneal réflex reduction \\
\hline CASK Mutation & CASK & Megalocornea \\
\hline \multirow[t]{2}{*}{ Gaucher disease } & Glucocerebrosidase & Corneal opacificación \\
\hline & Optineurin (autophagy receptor) & Keratoconus \\
\hline Hutchinson-Gilford progeria syndrome & LMNA & Some with dry eyes \\
\hline Marfan syndrome & Fibrillin, which causes increased TGF- $\beta 1$ & Flat and thinned cornea \\
\hline $\begin{array}{c}\text { Mitochondrial encephalomyopathy, lactic } \\
\text { acidosis and stroke-like episodes (MELAS) } \\
\text { syndrome }\end{array}$ & MT-ND1, MT-ND5, MT-TH, MT-TL1, and MT-TV & $\begin{array}{l}\text { Corneal and lens epithelial with paracrystalline } \\
\text { inclusions and elongated mitochondria[i] }\end{array}$ \\
\hline Microphthalmia syndromic 7 & $\begin{array}{l}\text { Mitochondrial holocytochrome synthase (HCCS), } \\
\text { which is essential for OXPHOS function }\end{array}$ & Opaque and small cornea \\
\hline Chanarin-Dorfman syndrome & $\begin{array}{l}\text { ABHD5; adipose triglyceride lipase (ATGL) gene } \\
\text { and its cofactor CGI-58 }\end{array}$ & Corneal opacity \\
\hline Werner syndrome & RecQ DNA ligase & Bullous keratopathy \\
\hline $\begin{array}{c}\text { Epidermolysis bullosa simplex with muscular } \\
\text { dystrophy (EBS-MD) }\end{array}$ & Plectin 1 (Plec1) gene & Dry eye, ectropion \\
\hline Ataxia telangiectasia & ATM & oculocutaneous telangiectasia \\
\hline Fanconi anemia complementation group A & FANCA & Microcornea \\
\hline Dyskeratosis congenita & $\begin{array}{l}\text { Telomerase RNA component (TERC)and } \\
\text { telomerase reverse transcriptase (TERT) }\end{array}$ & Corneal limbal insufficiency \\
\hline
\end{tabular}

Corneal disease in association with mitochondrial dysfunction have included astigmatism, corneal clouding in Fanconi syndrome [38], corneal dystrophy and corneal endothelial dysfunction in Pearson syndrome [39].

In cultured corneal epithelium, increase in ROS results in mitochondrial DNA damage [40]. Oxidative stress can have a role in pterygium formation [41], Fuchs' endothelial dystrophy [42] and corneal dystrophy [43]. Fuchs' endothelial dystrophy, that has a mutation in COL8A2, has been associated with mtDNA damage [44]. Thrombospondin 1 (THBS1) gene mutation can also cause mitochondrial dysfunction [45]. and dry eye [46].

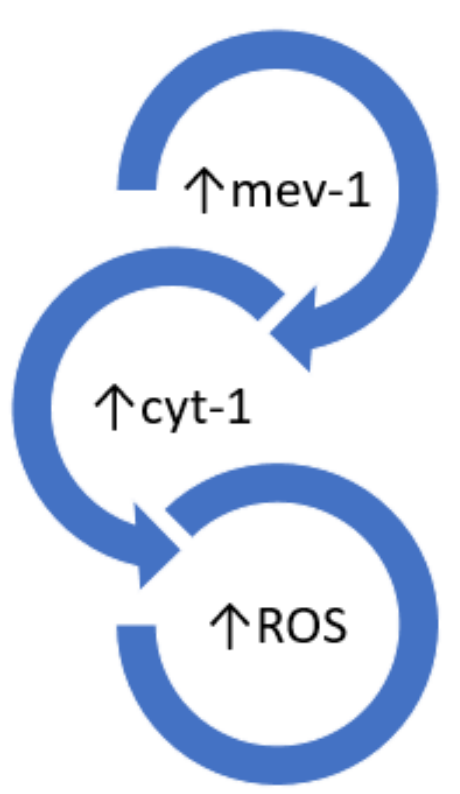

Figure 3: In the mev-1 animal model, the c-2 complex is compromised, leading to increased ROS production. These mice have lacrimal glad dysfunction and subsequent dry eye.
In a Tet-mev- 1 mouse model of dry eye, mev-1 is conditionally expressed, This causes mitochondrial dysfunction in the lacrimal glands reduced tear production and increased ROS production. Mev1 produces Cyt-1, which is part of C2 of mitochondria l OXPHOS. This has been shown to increase ROS, ocular surface damage, and decreased tear function (Figure 3) [49].

In another animal model, SIRT1, which is a component of mitochondria, was downregulated, and this resulted in tear film abnormalities, increased corneal fluorescein staining and ultimately dry eye disease [50].

In another animal model, rats underwent low humidity to induce dry eye, and were followed by stress markers Rab3d, Rab27b, Rab3d and syntaxin [51]. However, if the rats were placed on a calorie-restricted diet, which causes mitophagy [52], they had improved lacrimal function and healthier tear composition using the phenol red thread test post carbachol stimulation [53].

In humans, Sjøgren's Syndrome (SS) has been associated with mitochondrial dysfunction [54]. SS causes a vicious cycle of reduced lacrimal function, and the reduced tear production induces more ROS formation. This cycle causes a pathologic level in keratoepitheliopathy scores, goblet cell density and Schirmer tear value, all translating into dry eye [55].

A clinical study of 20 patients revealed that keratoconus was due to ROS from mitochondrial dysfunction in C1 [56]. When blink-suppressed dry eye is induced, a direct relationship to ROS is identified [57], causing surface inflammation [58], and decreased antioxidant enzymes levels [59]. Conjunctivitis complete ptosis, spontaneous corneal ulceration and keratitis have been reported in Kearns-Sayre syndrome [60], which is known to have mitochondrial DNA deletions [61]. Those having mtDNA deletion at bp 3895 had the greatest deletion load in the cornea [62]. Furthermore, endothelial or Descemet membrane abnormalities have caused 
corneal clouding in Kearns-Sayre syndrome [63]. Leigh syndrome, that can cause non-specific corneal changes, was documented to have abnormal appearing mitochondria and a mutation in mtDNA bp 8993 [64]. Other syndromes with mitochondrial dysfunction have shown ocular pathology. Mitochondrial neurogastrointestinal encephalopathy syndrome have shown nonspecific corneal changes [65]. Pontocerebellar hypoplasia can have mitochondrial aminoacyl-tRNA synthetases mutations [66].

Patients with Gaucher disease, with mutation of glucocerebrosidase, can present with corneal opacification [67] and mitochondrial dysfunction [68]. Optineurin is yet another important element for mitophagy. Abnormal optineurin expression has been documented in keratoconus formation [69]. TGF- $\beta 1$ has been shown to induce mitochondrial dysfunction and pro-fibrotic conditions [70]. In Marfan syndrome, a defective fibrilin causes increased levels of TGF- $\beta 1$, and symptoms, such as flattened and thinned cornea can be seen.

\section{The role of anti-oxidants in ocular surface health}

SkQ1 is an anti-oxidant that is mitochondria specific. When SkQ1, is applied to the eyes in a rabbit model, ROS production is prevented, TNF- $\alpha$ and IL- 6 is downregulated and IL-10 is upregulated. Corneal apoptosis is hence reduced. Furthermore [71]. resveratrol, which can induce mitophagy [72], has been shown to protect corneal epithelium from cytotoxic agents [73]. Polyunsaturated fatty acids in an animal model altered corneal neovascularization [74], but other studies have failed to reproduce these findings [75]. However, rapamycin, which regulates mitophagy, has shown to extend the survival of corneal cells in culture [76], and reduced scarring after keratectomy [77]. In vitro, rapamycin increased the colony forming efficiency of corneal cells [78] and reduced corneal cell senescence [79]. Ceramides are essential to corneal health [80], and their presence induce mitophagy and even tumor suppression [81].

\section{Conclusion}

In review of the published literature, mitochondria are intimately associated with oculocutaneous health and disease. We have reviewed the literature on the different diseases associated with mitochondrial dysfunction. We have also presented the current concepts of how mitochondria become dysfunctional. We already have a number of medications that act upon the mitochondria and alter mitochondrial function [82]. Many herbals touted as promoters of longevity and health, like resveratrol, are known to influence mitochondrial health. Now that the mechanisms are becoming clearer, we can use existing and newly designed drugs to improve mitochondrial health and with it, ocular surface and cutaneous health.

\section{References}

1. Schrier SA, Falk MJ (2011) Mitochondrial Disorders and The Eye. Curr Opin Ophthalmol 22(5): 325-331.

2. NunnariJ, Suomalainen A (2012) Mitochondria: In Sickness and in Health. Cell 148(6): 1145-1159.

3. McBride HM, Neuspiel, M Wasiak S (2006) Mitochondria: more than just a powerhouse. Current Biology 16(14): R551-60.
4. Andersson SG, Karlberg O, Canbäck B, Kurland CG (2003) On the origin of mitochondria: a genomics perspective. Philosophical Transactions of the Royal Society of London Series B, Biological Sciences 358(1429): 165-179.

5. Matilainen O, Quiros PM, Auwerx J (2017) Mitochondia and epigeneticscrosstalk in homeostasis and stress. Trends in Cell Biology 27(6): 453463.

6. Guerrero-Castillo S, Baertling F, Kownatzki D, Wessels HJ, Arnold S, et al. (2017) The assembly pathway of mitochondrial respiratory chain complex I. Cell Metab 25(1): 128-139.

7. Leone G, Abla H, Gasparre G, Porcelli AM, Lommarini L (2018) The Oncojanus Paradigm of Respiratory Complex I. Genes (Basel) 9(5): p.243.

8. Singh B, Schoeb TR, Bajpai P, Slominski A, Singh KV (2018) Reversing wrinkled sin and hair loss in mice restoring mitochondrial function. Cell Death \& Disease 9(735): 1-14.

9. Krutmamnn J, Schroeder P (2009) Role of mitochondria in photoaging of human skin: the defective powerhouse momdel. J Invest Dermatol Symp Proc 14(1): 44-49.

10. Miquel J, Economos AC, Fleming J, Johnson JE (1980) Mitochondrial role in cell aging. Exp Gerontol 15(6): 575-591.

11. Zeng L, Yang Y, Hu Y, Sun Y, Du Z, et al. (2014) Age-related decrease in the mitochondrial sirtuin deacetylase Sirt3 expression associated with ROS accumulation in the auditory cortex of the mimetic aging rat model. PLoS One 9(2): e88019.

12. Kim HS, Patel K, Muldoon-Jacobs K, Bisht KS, Aykin-Burns N, et al. (2010) SIRT3 is a mitochondria-localized tumor suppressor required for maintenance of mitochondrial integrity and metabolism during stress. Cancer Cell17(1): 41-52.

13. Dai SH, Chen T, Wang YH, Zhu J, Luo P, et al. (2014) Sirt3 protects cortical neurons against oxidative stress via regulating mitochondrial $\mathrm{Ca} 2+$ and mitochondrial biogenesis. Int J Mol Sci 15(8): 14591-14609.

14. Ding WX, Yin XM (2012) Mitophagy: mechanisms, pathophysiological roles, and analysis. Biol Chem. 393(7): 547-564.

15. Bartolome A, Garcia-Aguilar A, Asahara S, Kido Y, Guillén C, et al. (2017) mTORC1 Regulates both General Autophagy and Mitophagy Induction after Oxidative Phosphorylation Uncoupling. Molecular and Cellular Biology 37: e00441-e004417.

16. Li Q, Zhang T, Wang J, Zhang Z, Zhai Y, et al. (2014) Rapamycin attenuates mitochondrial dysfunction via activation of mitophagy in experimental ischemic stroke. Biochem Biophys Res Commun 444(2): 82-88.

17. Jin SM, Youle RJ (2012) PINK1- and Parkin-mediated mitophagy at a glance. J Cell Sci 125: 795-799.

18. Kalghatgi S, Spina CS, Costello JC, Liesa M, Morones-Ramirez JR, et al. (2013) Bactericidal antibiotics induce mitochondrial dysfunction and oxidative damage in mammalian cells. Science Translationanl Medicine 5(192): 192 ra85.

19. Moullan N, Mouchiroud L, Wang X, Ryu D, Williams EG, et al. (2015) Tetracyclines Disturb Mitochondrial Function across Eukaryotic Models: A Call for Caution in Biomedical Research. Cell Rep 10: 1681-1691.

20. Krutmann J, Gilchrest BA (2006) Skin Aging. In: Gilchrest BA, Krutmann J (Eds.), Springer, New York, USA, p. 33-44.

21. de Grey AD (2004) Mitochondrial mutations in mammalian aging: an over-hasty about-turn? Rejuvenation Research 7(3):171-174.

22. Berneburg M, Plettenberg H, Krutmann J (2000) Photoaging of human skin. Photodermatol Photoimmunol Photomed 16(6): 239-244.

23. Birch-Machin MA, Tindall M, Turner R, Haldane F, Rees JL (1998) Mitochondrial DNA deletions in human skin reflect photo- rather than chronologic aging. J Invest Dermatol 110(2): 149-152. 
24. Koch H, Wittern KP, Bergemann J (2001) In human keratinocytes the Common Deletion reflects donor variabilities rather than chronologic aging and can be induced by ultraviolet A irradiation. J Invest Dermatol 117(4): 892-897.

25. Schroeder P, Pohl C, Calles C, Marks C, Wild S, et al. (2007) Cellular response to infrared radiation involves retrograde mitochondrial signaling. Free Radic Biol Med 43(1): 128-135.

26. Brandon M, Baldi P, Wallace DC (2006) Mitochondrial mutations in cancer. Oncogene 25: 4647-4662.

27. Hamanaka RB, Chandel NS (2013) Mitochondrial metabolism as a regulator of keratinocyte differentiation. Cellular Logistics 3(1): e25456-1-e25456-5.

28. Gurgas L, Doru-Popescu N, Hangan T, Chirila S, Moroianu O, et al. (2018) Electron Microscopy Study of Nodular Basal Cell Carcinoma. ARS Medica Tomitana 24(2): 90-95.

29. Mamelak AJ, Kowalski J, Murphy K, Yadava N, Zahurak M, et al. (2005) Downregulation of NDUFA1 and other oxidative phosphorylationrelated genes is a consistent feature of basal cell carcinoma. Exp Dermatol 14: 336-348

30. Pradella LM, Lang M, Kurelac I, Mariani E, Guerra F, et al. (2013) Where Birt-Hogg-Dubé meets Cowden Syndrome: mirrored genetic defects in two cases of syndromic oncocytic tumours. Eur J Hum Genet 21(10): 1169-1172.

31. Awad F, Assrawi E, Louvrier C, Jumeau C, Giurgea I, et al. (2018) Photoaging and skin cancer: Is the inflammasome the missing link? Mech Ageing Dev 172: 131-137.

32. Ho J, de Moura MB, Yan Lin, Garret Vincent, Stephen Thorne, et al. (2012) Importance of glycolysis and oxidative phosphorylation in advanced melanoma. Mol Cancer 11: 76.

33. Maes H, Agostinis P (2014) Autophagy and mitophagy interplay in melanoma progression. Mitochondria 19: 58-68.

34. Seen S, Tong L (2018) Dry eye disease and oxidative stress. Acta Ophthalmologica 96(4): 1-9.

35. Karnati R, Talla V, Peterson K, Laurie GW (2016) Lacritin and Other Autophagy Associated Proteins in Ocular Surface Health. Exp Eye Res 144: 4-13.

36. Wang N, Zimmerman K, Raab RW, McKown RL, Hutnik CM, et al. (2013) Lacritin rescues stressed epithelia via rapid for head box 03 (FOXO3)associated autophagy that restores metabolism. J Biol Chem 288(25): 18146-18161.

37. Aluru SV, Agarwal S, Srinivasan B, Iyer GK, Rajappa SM, et al. (2012) Lacrimal proline rich 4 (LPRR4) protein in the tear fluid is a potential biomarker of dry eye syndrome. PloS One 7(12): 51979.

38. Lee JJ, Tripi LM, Erbe RW, Garimella-Krovi S, Springate JE (2012) A mitochondrial DNA deletion presenting with corneal clouding and severe Fanconi syndrome. Pediatr Nephrol 27(5): 869-872.

39. Kasbekar SA, Gonzalez-Martin JA, Shafiq AE, Chandna A, Willoughby CE (2013) Corneal endothelial dysfunction in Pearson syndrome. Ophthalmic Genet 34(1-2): 55-57.

40. Deng R, Hua X, Li J, Wei Chi, Zongduan Zhang, et al. (2015) Oxidative stress markers induced by hyperosmolarity in primary human corneal epithelial cells. PLoS ONE, 10(5): e0126561.

41. Balci M, Sahin S, Mutlu FM, Yağci R, Karanci P, et al. (2011) Investigation of oxidative stress in pterygium tissue. Mol Vis 17: 443-447.

42. Jurkunas UV, Bitar MS, Funaki T, Azizi B (2010) Evidence of oxidative stress in the pathogenesis of fuchs endothelial corneal dystrophy. Am J Pathol 177(5): 2278-2289.

43. Choi SI, Kim TI, Kim KS, Kim BY, Ahn SY, et al. (2009) Decreased catalase expression and increased susceptibility to oxidative stress in primary cultured corneal fibroblasts from patients with granular corneal dystrophy type II. Am J Pathol 175(1): 248-261.
44. Wojcik KA, Kaminska A, Blasiak J, Jerzy Szaflik, Jacek P Szaflik (2013) Oxidative Stress in the Pathogenesis of Keratoconus and Fuchs Endothelial Corneal Dystrophy. Int J Mol Sci 14(9) : 19294-19308.

45. Soto-Pantoja DR, Sipes JM, Martin-Manso G, Westwood B, Morris NL, et al. (2016) Dietary fat overcomes the protective activity of thrombospondin-1 signaling in the ApcMin/+ model of colon cancer. Oncogenesis 5(5): e230.

46. Tan X, Chen Y, William F, Afsaneh A, Yizhi L, et al. (2018) The immunoregulatory role of corneal epithelium-derived thrombospondin-1 in dry eye disease. The Ocular Surface 16: 470-477.

47. Rummelt V, Folberg R, Ionasescu V, Yi H, Moore KC (1993) Ocular Pathology of MELAS Syndrome with Mitochondrial DNA Nucleotide 3243 Point Mutation. Ophthalmology 100(12): 1757-1766.

48. Uchino Y, Kawakita T, Miyazawa M, Ishii T, Onouchi H, et al. (2012) Oxidative stress induced inflammation initiates functional decline of tear pro-duction. PLOS ONE 7(10): e45805.

49. Liu H, Sheng M, Liu Y, Wang P, Chen Y, et al. (2015) Expression of SIRT1 and oxidative stress in diabetic dry eye. Int J Clin Exp Pathol 8(6): 7644 7653.

50. Nakamura S, Shibuya M, Nakashima H, Hisamura R, Masuda N, et al. (2007) Involvement of oxidative stress on corneal epithelia alterations in a blink-suppressed dry eye. Invest Ophthalmol Vis Sci 48(4): 15521558.

51. Diot A, Morten K, Poulton J (2016) Mitophagy plays a central role in mitochondrial ageing. Mamm Genome 27(7-8): 381-395.

52. Kawashima M, Kawakita T, Okada N, Ogawa Y, Murat D, et al. (2010) Calorie restriction: a new therapeutic intervention for age-related dry eye disease in rats. Biochem Biophys Res Comm 397(4): 724-728.

53. Pagano G, Castello G, Pallardó FV (2013) Sjøgren's syndrome-associated oxidative stress and mitochondrial dysfunction: prospects for chemoprevention trials. Free Radic Res 47(2): 71-73.

54. Choi W, Lian C, Ying L, Kim GE, You IC, et al. (2016) Expression of lipid peroxidation markers in the tear film and ocular surface of patients with non-Sjogren syndrome: potential biomarkers for dry eye disease. Curr Eye Res 41(9): 1143-1149.

55. Pathak D, Nayak B, Singh M Sharma N, Tandon R, et al. (2011) Mitochondrial complex 1 gene analysis in keratoconus. Mol Vis 17: 1514-525

56. Nakamura S, Shibuya M, Nakashima H, Hisamura R, Masuda N, et al. (2007) Involvement of oxidative stress on corneal epithelial alterations in a blink-suppressed dry eye. Invest Ophthalmol Vis Sci 48(4): 15521558.

57. S.o.t.I.D.E. (2007) The definition and classification of dry eye disease: Report of the definition and classification subcommittee of the International Dry Eye WorkShop 2007. Ocul Surf 5(2): 75-92.

58. Cejkova J, Ardan T, Simonova Z, Cejka C, Malec J, et al. (2008) Decreased expression of antioxidant enzymes in the conjunctival epithelium of dry eye (Sjogren's syndrome) and its possible contribution to the development of ocular surface oxidative injuries. Histol Histopathol 23(12): 1477-1483

59. Schmitz K, Lins H, Behrens-Baumann W (2003) Bilateral spontaneous corneal perforation associated with complete external ophthalmoplegia in mitochondrial myopathy (Kearns-Sayre syndrome). Cornea 22(3): 267-270.

60. Moraes CT, Di Mauro S, Zeviani M, Lombes A, Shanske S, et al. (1989) Mitochondrial DNA Deletions in Progressive External Ophthalmoplegia and Kearns-Sayre Syndrome. NEJM 320(20): 1293-1299.

61. Gendron SP, Bastien N, Mallet JD, Rochette PJ (2013) The 3895-bp mitochondrial DNA deletion in the human eye: a potential involvement in corneal ageing and macular degeneration. Mutagenesis 28(2): 197 204. 
62. Al-Enezi M, Al-Saleh H, Nasser M (2008) Mitochondrial disorders with significant ophthalmic manifestations. Middle East Afr J Ophthalmol 15(2): 81-86

63. Hayashi N, Geraghty MT, Green WR (2000) Ocular histopathologic study of a patient with the T 8993-G point mutation in Leigh's syndrome. Ophthalmology 107(7): 1397-1402.

64. Barboni P, Savini G, Plazzi G, Bellan M, Valentino ML, et al. (2004) Ocular findings in mitochondrial neuro gastrointestinal encephalomyopathy: a case report. Graefes Arch Clin Exp Ophthalmol 242(10): 878-880.

65. Edvardson S, Shaag A, Kolesnikova O, Gomori JM, Tarassov I, et al. (2007) Deleterious mutation in the mitochondrial arginyl-transfer RNA synthetase gene is associated with Pontocerebellar Hypoplasia. Am J Hum Genet 81(4): 857-862.

66. Guemes A, Kosmorsky GS, Moodie DS, Clark B, Meisler D, et al. (1998) Corneal opacities in gaucher disease. American Journal of Ophthalmology 126(6): 833-835

67. Gegg ME, Schapira AHV (2016) Mitochondrial dysfunction associated with glucocerebrosidase deficiency. Neurobiol Dis 90: 43-50.

68. Wong YC, Holzbaur EL (2015) Temporal dynamics of PARK2/parkin and OPTN/optineurin recruitment during the mitophagy of damaged mitochondria. Autophagy 11(2): 422-424.

69. Patel AS, Song JW, Chu SG, Mizumura K, Osorio JC, et al. (2015) Epithelial Cell Mitochondrial Dysfunction and PINK1 Are Induced by Transforming Growth Factor- Beta1 in Pulmonary Fibrosis. PLOS one10(3): e0121246.

70. Zernii EY, Gancharova OS, Baksheeva VE, Golovastova MO, Kabanova EI, et al. (2017) Mitochondria-Targeted Antioxidant SkQ1 Prevents Anesthesia-Induced Dry Eye Syndrome. Oxid Med Cell Longev 9281519 17.

71. Wu J, Li X, Zhu G, Zhang Y, He M, et al. (2016) The role of Resveratrolinduced mitophagy/autophagy in peritoneal mesothelial cells inflammatory injury via NLRP3 inflammasome activation triggered by mitochondrial ROS. Exp Cell Res 341(1): 42-53.
72. Tsai TY, Chen TC, Wang IJ, Yeh CY, Su MJ, et al. (2015) The effect of resveratrol on protecting corneal epithelial cells from cytotoxicity caused by moxifloxacin and benzalkonium chloride. Invest Ophthalmol Vis Sci 56(3): 1575-1584.

73. Ormerod LD, Garsd A, Abelson MB, Kenyon KR (1990) Effects of altering the eicosanoid precursor pool on neovascularization and inflammation in the alkali-burned rabbit cornea. Am J Pathol,137(5): 1243-1252.

74. Ormerod LD, Garsd A, Abelson MB, Kenyon KR (1992) Eicosanoid modulation and epithelial wound healing kinetics of the alkali-burned cornea. J of Ocular Pharm 8(1): 53-58.

75. Gidfar S, Milani FY, Milani BY, Shen X, Eslani M, et al. (2017) Rapamycin Prolongs the Survival of Corneal Epithelial Cells in Culture. Scientific Reports 7: 40308.

76. Milani BY, Milani FY, et al. (2013) Rapamycin Inhibits the Production of Myofibroblasts and Reduces Corneal Scarring After Photorefractive Keratectomy. Invest Ophthalmol Vis Sci 54(12): 7424-7430.

77. Yousofimilani F, Milani B, Sagha H, Djalilian A (2013) Rapamycin helps to maintain colony forming efficiency in corneal epithelial cells. IOVS 54: 555.

78. Yousofimilani F, Milani B, Nezamabadi A, Afshar N, Djalilian A (2014) Inhibition of mTOR Pathway Reduces Senescence of Corneal Epithelial Cells in Culture. IOVS 55: 525

79. Brüggen B, Kremser C, Bickert A, Ebel P, Vom Dorp K, et al. (2016) Defective ceramide synthases in mice cause reduced amplitudes in electroretinograms and altered sphingolipid composition in retina and cornea. Eur J Neurosci 44(1): 1700-1713.

80. Dany M, Ogretmen B (2015) Ceramide induced mitophagy and tumor suppression. Biochimica et Biophysica Acta (BBA) - Molecular Cell Research 1853(10): 2834-2845.

81. Ebrahimi Fakhari D, Saffari A, Wahlster L, Sahin M (2017) Using tuberous sclerosis complex to understand the impact of mTORC1 signaling on mitochondrial dynamics and mitophagy in neurons. Autophagy 13(4): 754-756. 